\title{
Acute Intermittent Porphyria: Expression of Mutant and Wild-Type Porphobilinogen Deaminase in COS-1 Cells
}

\author{
Sami Mustajoki, ${ }^{1}$ Minna Laine, ${ }^{2}$ Maija Lahtela, ${ }^{3}$ Pertti Mustajoki, ${ }^{1}$ \\ Leena Peltonen, ${ }^{2}$ and Raili Kauppinen ${ }^{1}$ \\ ${ }^{1}$ Department of Medicine, Division of Endocrinology, Helsinki University Central \\ Hospital, Helsinki, Finland \\ ${ }^{2}$ Department of Human Molecular Genetics, National Public Health Institute, \\ Helsinki, Finland \\ ${ }^{3}$ Center for Scientific Computing, Espoo, Finland
}

Accepted April 23, 2000

\begin{abstract}
Background: Acute intermittent porphyria (AIP) is an autosomal dominant disorder that results from the partial deficiency of porphobilinogen deaminase (PBGD) in the heme biosynthetic pathway. Patients with AIP can experience acute attacks consisting of abdominal pain and various neuropsychiatric symptoms. Although molecular biological studies on the porphobilinogen deaminase (PBGD) gene have revealed several mutations responsible for AIP, the properties of mutant PBGD in eukaryotic expression systems have not been studied previously.

Materials and Methods: Seven mutations were analyzed using transient expression of the mutated polypeptides in COS-1 cells. The properties of mutated polypeptides were studied by enzyme activity measurement, Western blot analysis, pulse-chase experiments, and immunofluorescence staining. Results: Of the mutants studied, R26C, R167W, $\mathrm{R} 173 \mathrm{~W}, \mathrm{R} 173 \mathrm{Q}$, and $\mathrm{R} 225 \mathrm{X}$ resulted in a decreased enzyme activity (0-5\%), but R225G and 1073delA (elongated protein) displayed a significant residual
\end{abstract}

activity of $16 \%$ and $50 \%$, respectively. In Western blot analysis, the polyclonal PBGD antibody detected all mutant polypeptides except R225X, which was predicted to result in a truncated protein. In the pulse-chase experiment, the mutant polypeptides were as stable as the wild-type enzyme. In the immunofluorescence staining both wild-type and mutant polypeptides were diffusely dispersed in the cytoplasm and, thus, no accumulation of mutated proteins in the cellular compartments could be observed.

Conclusions: The results confirm the causality of mutations for the half normal enzyme activity measured in the patients' erythrocytes. In contrast to the decreased enzyme activity, the majority of the mutations produced a detectable polypeptide, and the stability and the intracellular processing of the mutated polypeptides were both comparable to that of the wild-type PBGD and independent of the cross-reacting immunological material (CRIM) class.

\section{Introduction}

Acute intermittent porphyria (AIP) is a metabolic disorder with an autosomal dominant

Address correspondence to: Sami Mustajoki, Department of Medicine, Division of Endocrinology, Helsinki University Central Hospital, P.O. Box 340, 00029 HYKS, Finland. Phone: +358-9-4717-2324; Fax: +358-9-4717-4012;

E-mail: sami.mustajoki@helsinki.fi pattern of inheritance (1). The disease results from the partial deficiency of porphobilinogen deaminase (PBGD; also known as hydroxymethylbilane synthase [EC 4.3.1.8]), which is the third enzyme in the heme biosynthetic pathway. PBGD activity is usually decreased to about $50 \%$ of normal when determined in patients' erythrocytes (2). The clinical manifestations of AIP vary even within families. Only $10-20 \%$ of 
patients experience occasional acute attacks, which consist of abdominal pain and various neuropsychiatric symptoms; however, milder symptoms typical for AIP are more common (3).

Biochemical and immunological studies have shown that AIP is attributable to a heterogenous group of biochemical defects, and the disease has previously been classified into four subtypes according to ratio of PBGD polypeptide concentration (cross-reacting immunological material [CRIM] negative and positive subtypes) to the enzyme activity in erythrocytes (4).

The crystal structure of E. coli PBGD indicates that the polypeptide chain is folded into three domains of similar sizes (5). Each of them is comprised of a $\alpha$-sheet, an $\beta$-helical secondary structure, and a hydrophobic core. PBGD catalyzes the polymerization of porphobilinogen yielding the linear tetrapyrrole, hydroxymethylbilane (preuroporphyrinogen). The reaction requires the presence of the dipyrromethane cofactor, which arises from the autocatalytic coupling of two porphobilinogen rings and is attached to the invariant cysteine-242 (human C261) in domain 3 (6). The cofactor stabilizes the enzyme (7), and it is not incorporated in the product but functions as a primer to which the four substrate molecules are sequentially attached $(6,8)$. The large volume of the active site cavity and the multipoint interaction between the enzyme and the growing polypyrrole chain imply that mutations altering multiple amino acids can result in deficient PBGD activity.

The PBGD gene has been sequenced and thoroughly characterized (9-14). The gene is assigned to chromosome 11q24.1-24.2 and it contains 15 exons. The size of the gene is approximately $10 \mathrm{~kb}$ of which $1.3 \mathrm{~kb}$ represent coding sequence. Two tissue-specific isoforms have been characterized. Both transcripts arise from two separate promoters via alternative splicing of exons 1 and 2. The mRNA of the housekeeping (nonerythropoietic) isoform contains exons 1 and 3-15, coding for an enzyme of 361 amino acids $(M \sim 42,000)$, whereas the erythroid isoform $(M \sim 40,000)$ is encoded by exons 2-15 lacking the first 17 amino acids of the amino terminus.

Recent molecular biological studies on the PBGD gene have revealed approximately 160 mutations responsible for AIP, limiting the potential of DNA diagnostics in this disease. We have previously characterized 26 mutations from 38 AIP families, which cover $95 \%$ of the 40 families known to have AIP in the Finnish population of 5 million (15-17). In addition, we have studied the steady-state mRNA levels of the mutant alleles in lymphocytes and shown large variations in the transcript levels among different mutants (18). These variations do not correlate with the CRIM class, the localization of the mutation in the PBGD gene, or the clinical phenotype of AIP. To further characterize the functional consequences of the mutations responsible for AIP, we have performed in vitro site-directed mutagenesis of seven different mutations in the PBGD gene and studied the transient expression of each mutated polypeptide in an eukaryotic cell line.

\section{Material and Methods}

Seven different mutations representing different CRIM classes, amino acid substitutions in the same codon, or a deletion removing normally utilized termination codon in the PBGD gene were chosen for this study (Table 1). All of them have previously been identified among Finnish AIP patients (15) and the steady-state transcript levels of the mutant alleles have previously been determined in the case of five mutations (18) (Table 1).

\section{Mutagenesis}

Mutagenesis was performed using the Chameleon Double-Stranded Site-Directed Mutagenesis Kit (Stratagene, CA) according to the manufacturer's instructions. The full-length coding region of the PBGD cDNA (19), used as a template, was ligated between the HindIII and EcoRI sites of mammalian expression vector SVpoly (20). Seven different mutant constructs were made: R26C, R167W, R173W, R173Q, R225G, R225X, and 1073delA. Oligonucleotides used in each mutagenesis reaction are given in Table 1. The selection primer was located in the polylinker region of SVpoly which removed the cleavage site for XbaI (Table 2). Mutant clones were confirmed by sequencing.

\section{COS-1 Cell Culture and DNA Transfection}

COS-1 cells were maintained in Dulbecco's modified Eagle's medium (Gibco BRL, U.K.) supplemented with $10 \%$ fetal heat-inactivated bovine serum and penicillin $(10000 \mathrm{U} / \mathrm{ml}$, Gibco BRL, U.K.) and streptomycin (10000 
Table 1. Characteristics of mutations

\begin{tabular}{|c|c|c|c|c|c|}
\hline \multicolumn{2}{|c|}{ Mutation $^{\mathbf{a}}$} & \multirow{2}{*}{$\begin{array}{c}\text { Outcome } \\
\text { R26C }\end{array}$} & \multirow{2}{*}{$\begin{array}{c}\begin{array}{c}\text { Corresponding } \\
\text { residue in } E . \text { coli }^{\mathrm{b}}\end{array} \\
\mathrm{R} 1 \mathrm{l}\end{array}$} & \multirow{2}{*}{$\begin{array}{c}\text { CRIM }^{\mathbf{c}} \\
+\end{array}$} & \multirow[t]{2}{*}{$\begin{array}{c}\text { Mutant mRNA } \\
\text { as a ratio of } \\
\text { wild type mRNA }\end{array}$} \\
\hline Exon 3 & $76 \mathrm{C} \rightarrow \mathrm{T}$ & & & & \\
\hline Exon 10 & $499 \mathrm{C} \rightarrow \mathrm{T}$ & R167W & R 149 & + & \\
\hline Exon 10 & $517 \mathrm{C} \rightarrow \mathrm{T}$ & R173W & $\mathrm{R} 155$ & $-1+$ & 0.97 \\
\hline Exon 10 & $518 \mathrm{G} \rightarrow \mathrm{A}$ & R173Q & $\mathrm{R} 155$ & + & 0.66 \\
\hline Exon 12 & $673 \mathrm{C} \rightarrow \mathrm{G}$ & R225G & R211 & - & 0.82 \\
\hline Exon 12 & $673 \mathrm{C} \rightarrow \mathrm{T}$ & R225X & R211 & - & 0.22 \\
\hline Exon 15 & 1073delA & Frame shift ${ }^{\mathrm{e}}$ & & - & 0.72 \\
\hline \multicolumn{6}{|l|}{${ }^{a}(15)$} \\
\hline \multicolumn{6}{|c|}{$\mathrm{b}(36)$} \\
\hline \multicolumn{6}{|c|}{ ' CRIM, cross-reactive immunologic material(27) } \\
\hline \multicolumn{6}{|c|}{ e Original termination codon abolished } \\
\hline
\end{tabular}

$\mathrm{U} / \mathrm{ml})$. For transfection, the cells were seeded on a $3-\mathrm{cm}$ 6-well plate at 400,000 cells/well and grown overnight. The cells were transfected with $1.5 \mu \mathrm{g}$ of the plasmid construct by lipofection (21) using FuGENE 6 transfection reagent (Boehringer Mannheim, Germany). The medium was replaced on the next day, and $48 \mathrm{hr}$ post-transfection the cells were either harvested for the PBGD activity and Western blot analyses or the pulse-chase experiment was performed.

\section{Enzyme Activity Assay}

One hundred $\mu \mathrm{l}$ of the cell lysate in $1.0 \mathrm{ml}$ of $1 \%$ Triton X-100 were pre-incubated at $37^{\circ} \mathrm{C}$ for $15 \mathrm{~min}$ prior to adding $500 \mu \mathrm{l}$ of $1.4 \mathrm{mM}$ porphobilinogen in phosphate-citrate buffer (pH 7.5 ) (22). The mixture was incubated for $30 \mathrm{~min}$ at $37^{\circ} \mathrm{C}$ and the reaction was stopped with $2.5 \mathrm{ml}$ of $10 \%$ trichloroacetic acid. The fluorescence of the supernatant was measured using $100 \mu \mathrm{g} / \mathrm{l}$ uroporphyrin I standard at the excitation wavelength $407 \mathrm{~nm}$ and the emission wavelength $598 \mathrm{~nm}$. The protein concentration in the cell lysate was determined by the dye-binding reaction (Bio-Rad Protein Assay, Bio- Rad, CA). One unit of the PBGD activity equals the amount of enzyme forming 1 nmole of uroporphyrin $/ \mathrm{hr}$ at $37^{\circ} \mathrm{C}$. An expression vector control was used to monitor the background expression of PBGD in COS-1 cells.

Table 2. Primers for mutagenesis ${ }^{a}$

\begin{tabular}{|c|c|}
\hline $76 \mathrm{C} \rightarrow \mathrm{T}$ & 5'-CGC GTG GGT ACC TGC AAG AGC CAG-3' \\
\hline $499 \mathrm{C} \rightarrow \mathrm{T}$ & 5'-CAG GAG TAT TTG GGG AAA CCT CAA CAC C-3' \\
\hline $517 \mathrm{C} \rightarrow \mathrm{T}$ & 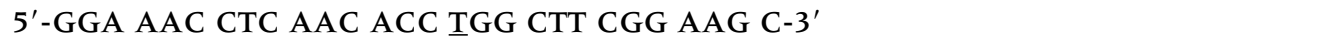 \\
\hline $518 \mathrm{G} \rightarrow \mathrm{A}$ & $\begin{array}{l}\text { 5'-CGG GGA AAC CTC AAC ACC CÄG CTT CGG AAG CTG GAC GAG CAG CAG GAG } \\
\text { TTC AGT GCC ATC AT-3' }\end{array}$ \\
\hline $673 \mathrm{C} \rightarrow \mathrm{G}$ & 5'-GGG CGT GGA AGT G $\underline{G}$ AGC CAA GGA CCA G-3' \\
\hline $673 \mathrm{C} \rightarrow \mathrm{T}$ & 5'-GGG CGT GGA AGT GTG AGC CAA GGA CCA G-3' \\
\hline 1073delA & 5'-GCA CGG CAG CTT_ ACG ATG CCC ATT-3' \\
\hline Selection primer ${ }^{\mathrm{b}}$ & 5'-GGA GTC TGG AGT CTC GAC GGC TCA GAT AGC-3' \\
\hline
\end{tabular}

\footnotetext{
${ }^{a}$ Mutation site underlined.

${ }^{\mathrm{b}}$ Restriction site for $\mathrm{Xba \textrm {I }}(\mathrm{A} \rightarrow \mathrm{C})$ removed.
} 


\section{Western Blot}

A mixture of $20 \mu$ l of cell lysate in phosphatebuffered saline (PBS) containing 1\% Triton $\mathrm{X}-100,5 \mu \mathrm{l}$ of $5 \times$ Laemmli's reagent (23), $1 \mu \mathrm{l}$ dithiotreitol, and $1 \mu \mathrm{l}$ of $20 \%$ SDS was run in a $14 \%$ SDS-polyacrylamide gel. The gel was electroblotted on a nitrocellulose filter (TransBlot, Bio-Rad). The filter was filled with 5\% bovine milk proteins and reacted with a $1: 2000$ dilution of polyclonal rabbit anti-human-PBGD antibody (24). The anti-rabbit IgG-alkaline phosphatase conjugate (1:7500, Promega, WI) was used as a secondary antibody and the proteins were visualized using $0.66 \%$ nitro blue tetrazolium (NBT, Promega) and 0.33\% 5-bromo-4-chloro-3-indolyl-1-phosphate (BCIP, Promega).

\section{Pulse-Chase and Immunoprecipitation}

The cells were starved in the cysteine- and methionine-free medium for $60 \mathrm{~min}$ before labeling with $200 \mu \mathrm{Ci} / \mathrm{ml}$ Promix $\left({ }^{35} \mathrm{~S}-\mathrm{Cys}+\right.$ ${ }^{35}$ S- Met, Amersham, U.K.). A 1-hr pulse was followed by a 1- to 23-hr chase in the normal medium without the bovine serum. After the chase period the cells were harvested and resuspended in PBS containing 1\% Triton X-100 and lysed by freeze-thawing three times.

The PBGD proteins were immunoprecipitated from the cell lysates using polyclonal rabbit PBGD antibodies (1:2000) (24) and formalinfixed Staphylococcus aureus cells (Pansorbin cells, Calbiochem, CA) (25). The labeled and precipitated proteins were separated by $14 \%$ SDS-polyacrylamide gel and visualized by autoradiography.

\section{Immunofluorescence}

For immunofluorescence staining the transfected COS-1 cells were grown on 12-mm coverslips and fixed in $3 \%$ paraformaldehyde for $30 \mathrm{~min}$ at room temperature. After fixation, the cells were washed in PBS and permeabilized and blocked in PBS containing $0.2 \%$ saponin, $0.5 \%$ bovine serum albumin (BSA) for $30 \mathrm{~min}$ at room temperature. This was followed by incubation with a 1:2000 dilution of PBGD antibody for $30 \mathrm{~min}$ at room temperature. The cells were washed in PBS containing $0.2 \%$ saponin and $0.5 \%$ BSA and incubated with a 1:150 dilution of the rhodamine-conjugated secondary antibody against rabbit immunoglobulins (Immunotech, MA) in PBS for $45 \mathrm{~min}$ at room temperature. Cells were washed in PBS and mounted on slides in $87 \%$ glycerol.

\section{Protein Modeling}

A model of PBGD was constructed using the MSI/InsightII from the refined coordinates of the E. coli enzyme (IPDA). A single amino acid substitution was created by replacing the side chain of arginine with the side chain of glycine. The rotamers of the glycine side chain were studied. The model was energy minimized.

\section{Results}

Twelve of 58 conserved amino acids in PBGD are arginine residues. We have previously identified substitutions in six of them among Finnish AIP patients (Table 1) (18). The majority of arginines, which are scattered throughout all three domains, are suspected to be crucial for the enzyme activity because of interaction with the substrate or binding of the cofactor (26). The R26C, R167W, and R173Q amino acid changes are identified among CRIM-positive patients, whereas patients having the other mutations have been CRIM negative (27). The R173W substitution is, however, associated with both CRIM classes. The seventh mutation analyzed is a single base pair deletion in exon 15 (1073delA), which is predicted to remove the termination codon without creating a new stop codon before the polyadenylation signal. Mutant constructs were expressed in COS-1 cells followed by PBGD activity measurements, and pulse-chase and immunofluorescence studies.

\section{Effect of Substitution on PBGD Activity}

Table 3 shows the results of the PBGD activity assay in COS cells $48 \mathrm{hr}$ post transfection. The cells were transfected either with the PBGD mutants, the wild-type PBGD, or the vector alone. The enzyme activities obtained were compared to that of the background activity of PBGD in COS-1 cells. In five cases (R26C, R167W, R173W, R173Q, R225X), the PBGD activity was reduced to close to the background level (0-5\%), confirming the causality of the amino acid substitution and the low PBGD activity measured in the patients' erythrocytes. In 
Table 3. PBGD activity assay after expression in COS-1 cells

\begin{tabular}{lcr}
\hline Construct & $\begin{array}{c}\text { Enzyme activity ( } \pm \text { S.E.) } \\
\text { nmol/mg prot/h }\end{array}$ & $\begin{array}{c}\text { Percentage of wild } \\
\text { type activity }\end{array}$ \\
\hline SVpoly-PBGD & $3173( \pm 507)$ & $100 \%$ \\
SVpoly-PBGD-R26C & $105( \pm 17)$ & $0 \%$ \\
SVpoly-PBGD-R167W & $273( \pm 66)$ & $5 \%$ \\
SVpoly-PBGD-R173W & $173( \pm 33)$ & $1 \%$ \\
SVpoly-PBGD-R173Q & $140( \pm 11)$ & $0 \%$ \\
SVpoly-PBGD-R225G & $626( \pm 78)$ & $16 \%$ \\
SVpoly-PBGD-R225X & $142( \pm 9)$ & $0 \%$ \\
SVpoly-PBGD + 43 aa (1073delA) & $50 \%$ \\
SVpoly & $1660( \pm 174)$ & $0 \%$ \\
H 2 O & $131( \pm 3)$ & $0 \%$ \\
COS-1 cells, not transfected & $113( \pm 13)$ & $0 \%$ \\
\end{tabular}

a Mean value of four independent transfections.

${ }^{\mathrm{b}}$ Corrected with the endogenous COS-1 PBGD activity

two cases (R225G, 1073delA), the enzyme activity was only partially disturbed showing a residual activity of $16-50 \%$. The enzyme activities expressed by the mutations found among CRIM-positive or CRIM-negative patients did not differ significantly.

\section{Analyses of Mutant Polypeptides}

The mutant constructs (SVpoly-PBGD-C26, -W167, -W173, -Q173, and-G225) expressed a polypeptide that reacted with the antibodies raised against human PBGD and the size of it was comparable with that of the normal enzyme (Fig. 1). As predicted, the construct with the mutation 1073 delA removing the termination codon produced a longer polypeptide. Only the SVpoly-PBGD-225X, which was predicted to produce a truncated protein owing to a premature termination codon after 224 amino acids, failed to produce a detectable polypeptide in Western blot analysis.

According to immunofluorescence staining, the transfection efficiency using the lipofection method was approximately $20 \%$ (data not shown) being independent of the construct composition. The cellular localization of the mutant polypeptides was indistinguishable from that of the wild-type protein being diffusely dispersed in the cytoplasm (Fig. 2). Thus, no accumulation of the mutated proteins in the cellular compartments could be observed. The mutant constructs of different CRIM classes did not differ from each other in their cellular distribution.

Figure 3 demonstrates the results of the pulse-chase experiment. Because the signals of the mutated polypeptides remained similar to that of the wild-type protein at all time points studied, the mutated proteins were as stable as the wild-type protein. After $23 \mathrm{hr}$ chase both the mutants and the wild-type PBGD degraded in a similar manner resulting in a weaker signal in immunoprecipitation.

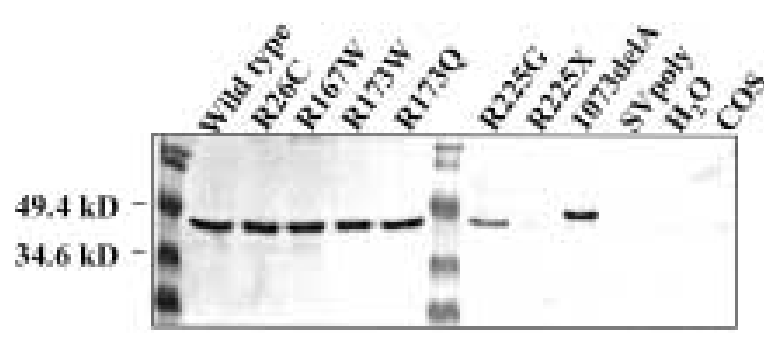

Fig. 1. Western blot analysis of the wild-type and mutated polypeptides. To visualize the PBGD polypeptides expressed by the wild-type and mutated constructs, cell lysates were run on a SDS polyacrylamide gel, transferred onto a nitrocellulose filter, and immunostained using a polyclonal rabbit PBGD antibody. 

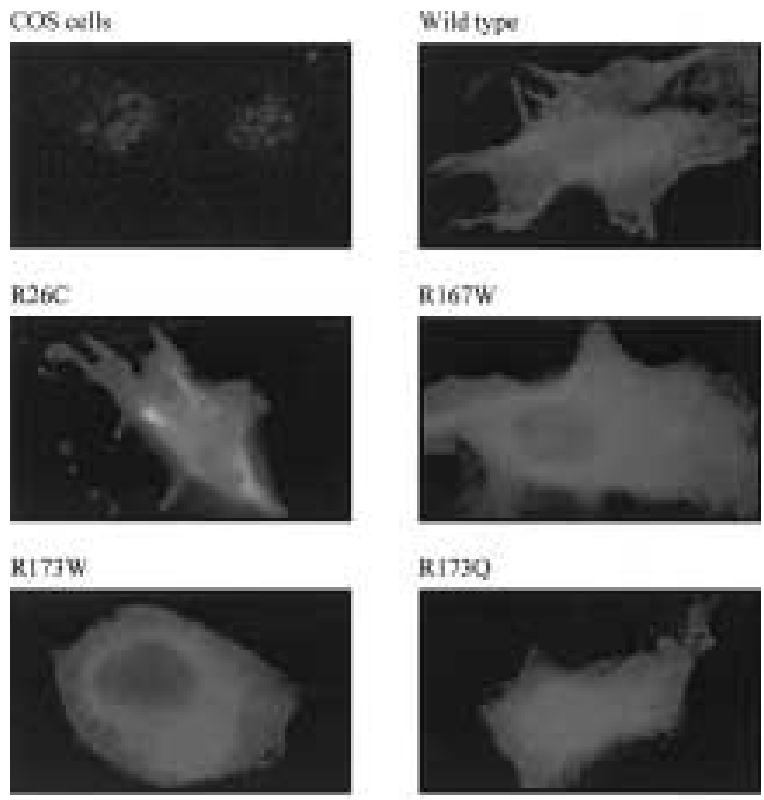

R2250
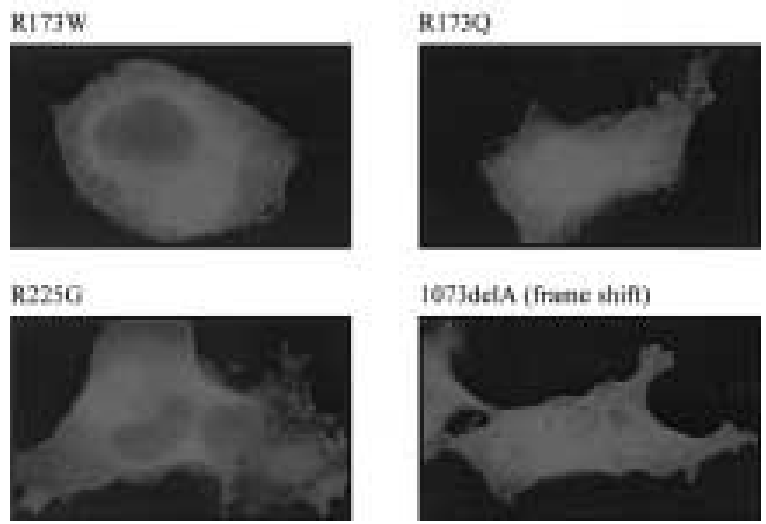

1073delA (frane ahiff)

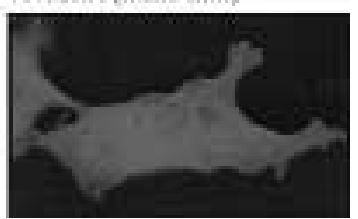

Fig. 2. Immunofluorescence of the mutated and wild-type PBGD after expression. Polyclonal rabbit antiserum followed by rhodamine conjugated anti-rabbit IgG was used to localize PBGD in fixed cells. Original magnification $\times 630$.

\section{Discussion}

We studied the properties of the mutated human PBGD in a eukaryotic expression system. All mutated constructs resulted in decreased PBGD activity, thus confirming the causality of the mutations and the half normal enzyme activity measured in the patients' erythrocytes. In addition, the majority of the mutant alleles produced a detectable polypeptide. Furthermore, the stability and the cellular processing of the mutated polypeptides were comparable to that of the wild-type PBGD and they were independent of the CRIM class.

Mutagenesis studies in E. coli have shown that arginine substitutions usually result in a dramatic decrease in PBGD activity $(28,29)$. The three-dimensional model of PBGD enables a comparison of the mutant and normal residues in the E. coli crystal structure and provides information about the structural and functional properties of the PBGD polypeptide (26). Previously, three reports have been published in which the

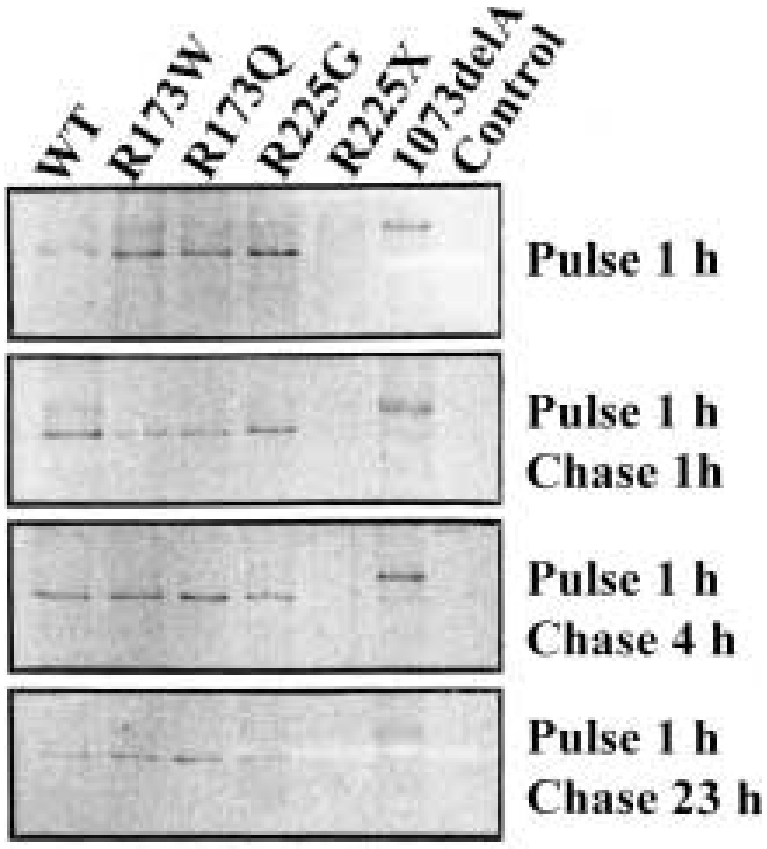

Fig. 3. Pulse-chase expression analysis of the wild-type and mutant PBGD polypeptides in COS-1 cells. During 1-hr pulse, all synthesized polypeptides were labeled with ${ }^{35} \mathrm{~S}$-cysteine and ${ }^{35} \mathrm{~S}$-methionine, and thereafter synthesized proteins were chased for 1, 4, and $23 \mathrm{hr}$, respectively. The wild-type and mutant polypeptides were immunoprecipitated and visualized by autoradiography after running the samples on an SDS-PAGE.

consequences of mutations responsible for AIP have been analyzed in a prokaryotic expression system (30-32). All mutations studied (R26H, V93F, R116W, R167Q, R173Q, R201W, C247F, and $\mathrm{W} 283 \mathrm{X}$ ) resulted in decreased enzyme activity.

\section{$R 26 C, R 173 W$, and $R 173 Q$}

Substitution of arginine by cysteine at position 26 or by glutamine or tryptophan at position 173 resulted in a dramatic decrease in PBGD activity to $0-1 \%$ of normal. Previously, the corresponding arginines in E. coli (R11 and R155) have been replaced by leucine (29) or histidine (28), and the mutant proteins have exhibited a trace amount of residual activity $(0.3 \%)$. The $26 \mathrm{H}$ and $173 \mathrm{Q}$ substitutions displayed a minor residual activity $(<4 \%)$ in bacterial cells (32), indicating no major discrepancy between proand eukaryotic expression systems. The two arginine residues interact with the substrate, 
and different amino acid substitutions at these positions inhibit the attachment of the first porphobilinogen to the cofactor-enzyme complex (28), which is detrimental to the function of the enzyme.

\section{R167W}

The residue $\mathrm{R} 167$ interacts with the side chain of the cofactor (26). The modification of residue R149 in E. coli (equivalent to human 167) to histidine results in an accumulation of the ES intermediate, that is, PBGD with a single porphobilinogen attached (28) and a similar perturbation might be expected for R167W (26). Because the mutant polypeptide displayed residual activity of $5 \%$, the substitution of arginine to tryptophan was not completely deleterious to the function of PBGD. Whether this minor residual activity has clinical implications in heterozygous patients is not known but at least it enables patients with compound heterozygosity (R167W, R167Q) to survive (33). When expressed in E. coli $(28,29)$ the mutant constructs with similar arginine substitutions exhibited $25-40 \%$ of that of the wild-type activity.

\section{$R 225 G$}

The mutant construct with glycine at position 225 displayed residual activity of approximately one-sixth of that of the wild type. Because this residue is conserved in different species, it has been presumed to have an important role in the structure or function of the enzyme (29). Arginine-225 is part of an $\alpha$-helix structure located on the outer surface of the protein (Fig. 4). Because glycine, unlike arginine, does not usually form $\alpha$-helix structures, the substitution probably alters the three-dimensional structure of PBGD (34). Furthermore, arginine 211 in $E$. coli, corresponding to the human residue 225, forms a stabilizing hydrogen bond with aspartic acid at position 3. Glycine is not capable of forming hydrogen bonds (35) and thus the substitution is more likely to cause a structural defect by destabilizing the enzyme.

\section{$R 225 X$}

This mutation, resulting in a truncated protein, displayed neither detectable polypeptide nor enzymatic activity. The predicted length of the mutant polypeptide is approximately twothirds of the size of the PBGD and domain 3 is totally untranslated. The truncated polypeptide is probably unstable because of a folding defect resulting in a total inactivation of the enzyme. Furthermore, the amount of mutant mRNA is dramatically decreased in these patients' lymphocytes, being $\sim 20 \%$ of the level of the normal allele (Table 1) (18). Because only a trace amount of the transcript is present, the synthesis of PBGD polypeptide is inevitably impaired.

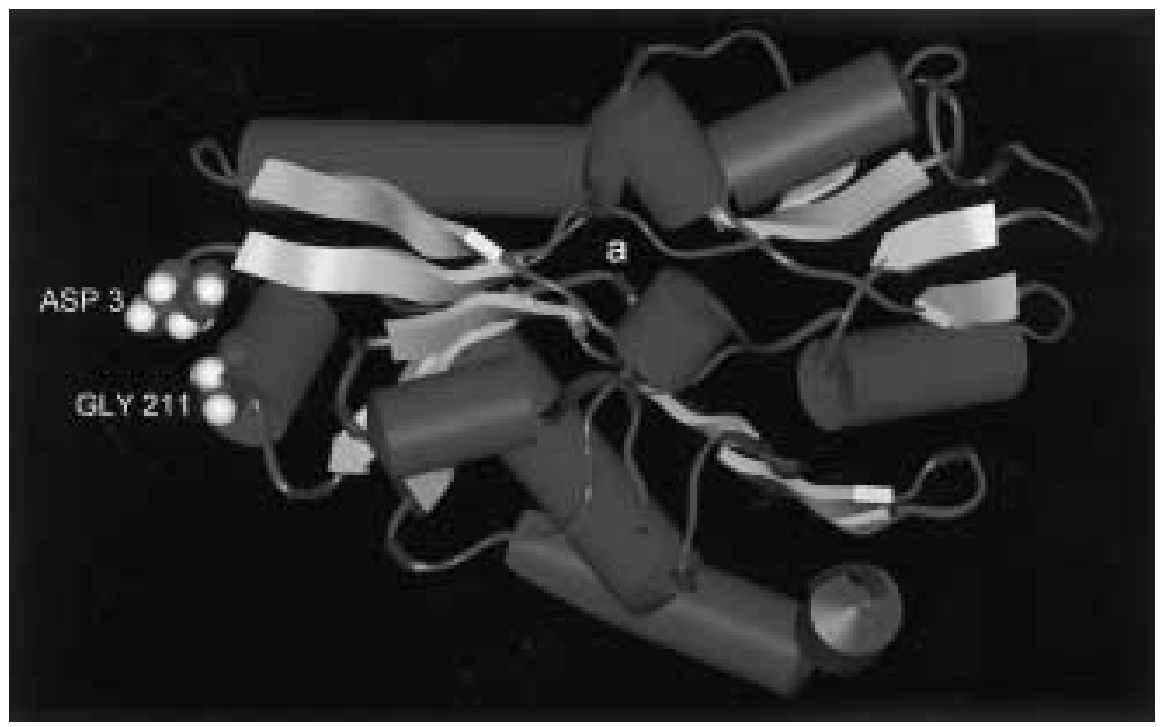

Fig. 4. A model of PBGD constructed from the refined coordinates of the $E$. coli enzyme. The mutation R211G (corresponding to the human mutation R225G) is located on the outer surface of the polypeptide and disrupts the hydrogen bond with aspartic acid at position 3. a, active site of the enzyme. 


\section{3delA}

This mutation has the highest residual activity of the mutants studied. The mutated polypeptide contains all the components known to be essential for the enzymatic function, but it includes an additional tail because the stop codon is lacking. Moreover, the polypeptide encoded by the SVpoly-PBGD-1073delA is not completely identical with the PBGD in vivo. The length of the predicted polypeptide in vivo would be 448 amino acids if the 3'-UTR region before the polyadenylation signal is translated, whereas in the construct a termination codon is introduced after a total of 404 amino acids. The additional tail at the end of the polypeptide may affect the enzymatic activity by altering the three-dimensional structure of the polypeptide and in vivo cause destabilization of the enzyme.

\section{Protein Analyses}

If a sufficient amount of porphobilinogen is present to form more stable tetrapyrrole-bound intermediates, the half-life of the erythroid form of PBGD is approximately $24 \mathrm{hr}$ (7). If the amount of porphobilinogen is inadequate, the polypeptide degrades more rapidly and the half-life is about $10 \mathrm{hr}$ (7). In the mammalian expression system that we used, the COS-1 cells were transfected with the housekeeping form of SVpoly PBGD-cDNA without additional porphobilinogen. Under these conditions, when the enzyme is expressed without regulation, the amount of endogenous porphobilinogen is probably insufficient to bind every molecule synthesized, leading to more rapid degradation. The protein turnover may be seen in the pulse-chase experiment in which all proteins studied were degrading after the 23-hr chase period. The mutant $\mathrm{R} 225 \mathrm{X}$ could not be detected using the polyclonal PBGD antibody in either immunoblotting or immunoprecipitation, suggesting either that the truncated polypeptide is unstable or that the polyclonal antibody did not recognize it.

Previously, the CRIM activity was determined by rocket-immunoelectrophoresis in which the polyclonal rabbit anti-human-PBGD antibody was used against PBGD obtained from lysed erythrocytes (4). Based on these results, the disease has previously been divided into four subclasses (27). In CRIM-negative patients (types 1 and 2), the amount of immunoreactive PBGD in erythrocytes has corresponded to the enzyme activity, but the amount of inactive PBGD has varied among CRIM-positive patients (types 1 and 2). In normal individuals and in CRIM-negative patients, the ratio of the immunoreactive protein and the enzyme activity is 1 but in CRIMpositive patients 1.6-5.2, respectively.

Several mechanisms have been proposed to explain the difference in CRIM classes: instability of mutant mRNA, insufficient translation, or rapid intracellular decay of the mutant polypeptide (27). When the steady-state levels of the mutant mRNA of five mutations in the PBGD gene were studied (Table 1), the mutant transcript levels in lymphocytes varied from 22-97\% independently of the CRIM class (18). In the case of the CRIM-negative mutations R225G and 1073delA, the mutant mRNA levels and residual activities were relatively high suggesting that CRIM status would rather depend on the degradation of the enzyme. According to the pulse-chase experiment, in which PBGD is overexpressed however, the mutant polypeptides were as stable as the wild type. Furthermore, the localization of the mutant polypeptides in the cytoplasm did not differ from that of the wild type. These results demonstrate that translation is adequately efficient to produce a protein that is comparable in stability with that of the wild type and excludes a major folding defect in these mutants. However, it may be that they do have a minor folding defect. If this is the case for R225G and 1073delA mutants, the inactive portions of these PBGD molecules (50-80\% of total) may be degraded more rapidly under in vivo than in vitro conditions.

\section{Acknowledgments}

We thank professor Bernard Grandchamp for providing us with the original PBGD CDNA and Drs Stig Thunell and Ylva Floderus for providing us with the PBGD antibody. This study was supported by grants from the University of Helsinki, the Academy of Finland, the Research Funds, and the Clinical Research Institute of the Helsinki University Central Hospital.

\section{References}

1. Kappas A, Sassa S, Galbraith RA, Nordmann Y. (1995) The porphyrias. In Scriver CR , Beaudet AL, Sly WS, Valle D (eds.) The Metabolic and 
Molecular Bases of Inherited Diseases. McGraw-Hill, New York, pp. 2103-2159.

2. Meyer UA, Strand LJ, Doss M, Rees C, Marver HS. (1972) Intermittent acute porphyri-demonstration of genetic defect in porphobilinogen metabolism. New Engl. J. Med. 286: 1277-1282.

3. Kauppinen R, Mustajoki P. (1992) Prognosis of acute intermittent porphyria: occurrence of acute attacks, precipitating factors and associated disease. Medicine 71: 1-13.

4. Anderson PM, Reddy RM, Anderson KM, Desnick RJ. (1981) Characterization of the porphobilinogen deaminase deficiency in acute intermittent porphyria. J. Clin. Invest. 68: 1-12.

5. Louie GV, Brownlie PD, Lambert R, et al. (1992) Structure of porphobilinogen deaminase reveals a flexible multidomain polymerase with a single catalytic site. Nature 359: 33-39.

6. Jordan PM, Warren MJ. (1987) Evidence for a dipyrromethane cofactor at the catalytic site of $E$. coli porphobilinogen deaminase. FEBS Lett. 225: 87-92.

7. Beaumont C, Grandchamp B, Bogard M, de Verneuil H, Nordmann Y. (1986) Porphobilinogen deaminase is unstable in the absence of its substrate. Biochim. Biophys. Acta 882: 384-388.

8. Warren MJ, Jordan PM. (1988) Investigation into the nature of substrate binding to the dipyrromethane cofactor of Eschericia coli porphobilinogen deaminase. Biochemistry 27: 9020-9030.

9. Raich N, Romeo PH, Dubart A, Beaupain D, Cohen-Solal M, Goossens M. (1986) Molecular cloning and complete primary sequence of human erythrocyte PBG deaminase. Nucleic Acids Res. 14: 5955-5968.

10. Grandchamp B, de Verneuil H, Beaumont C, Chretien S, Walter O, Nordmann Y. (1987) Tissue-specific expression of porphobilinogen deaminase: two isoenzymes from a single gene. Eur. J. Biochem. 162: 105-110.

11. Chretien S, Dubart A, Beaupain D, et al. (1988) Alternative transcription and splicing of the human porphobilinogen deaminase result either in tissue-specific or in house-keeping expression. Proc. Natl. Acad. Sci. U. S. A. 85: 6-9.

12. Lee J. (1991) Molecular genetic investigation of the human porphobilinogen deaminase gene in acute intermittent porphyria. Academic dissertation. Karolinska Institute, Stockholm, Sweden.

13. Namba H, Narahara K, Tsuji K, Yokoyama Y, Seino Y. (1991) Assignment of human porphobilinogen deaminase to 11q24.1-q24.2 by in situ hybridization and gene dosage studies. Cytogenet. Cell. Genet. 57: 105-108.

14. Yoo HW, Warner CA, Chen CH, Desnick RJ. (1993) Hydroxymethylbilane synthase: complete genomic sequence and amplifiable polymorphisms in the human gene. Genomics 15: 21-29.

15. Kauppinen R, Mustajoki S, Pihlaja H, Peltonen L, Mustajoki P. (1995) Acute intermittent por- phyria in Finland: 19 mutations in the porphobilinogen deaminase gene. Hum. Mol. Genet. 4: 215-222.

16. Mustajoki S, Pihlaja H, Ahola H, Mustajoki $P$, Kauppinen R. (1998) Three splicing defects, an insertion, and two missense mutations responsible for acute intermittent porphyria. Hum. Genet. 102: 541-548.

17. Mustajoki S, Ahola H, Mustajoki P, Kauppinen R. (1999) Insertion of Alu element responsible for acute intermittent porphyria. Hum. Mutat. 13: 431-438.

18. Mustajoki S, Kauppinen R, Mustajoki P, Suomalainen A, Peltonen L. (1997) Steady-state transcript levels of the porphobilinogen deaminase gene in patients with acute intermittent porphyria. Genome Res. 7: 1054-1060.

19. Grandchamp B, Picat C, de Rooij FWM, et al. (1989) A point mutation G-A in exon 12 of the porphobilinogen deaminase gene results in exon skipping and is responsible for acute intermittent porphyria. Nucleic Acids Res. 17: 66376649.

20. Stacey A, Schnieke A. (1990) SVpoly: a versatile mammalian expression vector. Nucleic Acids Res. 18: 2829.

21. Felgner PL, Gadek TR, Holm M, et al. (1987) Lipofection: a highly efficient, lipid mediated DNA- transfection procedure. Proc. Natl. Acad. Sci. U. S. A. 84: 7413-7417.

22. Ford RE, Ou C-N, Ellefson RD. (1980) Assay of erythrocyte uroporphyrinogen I synthase activity, with porphobilinogen as substrate. Clin. Chem. 26: 1182-1185.

23. Laemmli U. (1970) Cleavage of structural proteins during the assembly of the head of bacteriophage T4. Nature 227: 680-685.

24. Lannfelt L, Wetterberg L, Lilius L, Thunell S, Gellefors P. (1989) ELISA for measuring porphobilinogen deaminase in human erythrocytes. Clin. Chim. Acta 183: 227-238.

25. Proia R, D'Azzo A, Neufeld EF. (1984) Association of alpha- and beta-subunits during biosynthesis of beta-hexosaminidase in cultured fibroblasts. J. Biol. Chem. 259: 3350-3354.

26. Brownlie PD, Lambert R, Louie GV, et al. (1994) The three-dimensional structures of mutants of porphobilinogen deaminase: toward an understanding of the structural basis of acute intermittent porphyria. Prot. Sci. 3: 1644-1650.

27. Mustajoki P, Desnick RJ. (1985) Genetic heterogeneity in acute intermittent porphyria: characterization and frequency of porphobilinogen deaminase in Finland. Brit. Med. J. 291: 505-509.

28. Jordan PM, Woodcock SC. (1991) Mutagenesis of arginine residues in the catalytic cleft of Escherichia coli porphobilinogen deaminase that affects dipyrromethane cofactor assembly and tetrapyrrole chain initiation and elongation. Biochem. J. 280: 445-449. 
29. Lander M, Pitt AR, Alefounder PR, Bardy D, Abell C, Battersby AR. (1991) Studies on the mechanism of hydroxymethylbilane synthase concerning the role of arginine residues in substrate binding. Biochem. J. 275: 447-452.

30. Delfau MH, Picat C, de Rooij FWM, et al. (1990) Two different point $\mathrm{G}$ to A mutations in exon 10 of the porphobilinogen deaminase gene are responsible for acute intermittent porphyria. J. Clin. Invest. 86: 1511-1516.

31. Chen C-H, Astrin KH, Lee G, Anderson KE, Desnick RJ. (1994) Acute intermittent porphyria: identification and expression of exonic mutations in the hydroxymethylbilane synthase gene. J. Clin. Invest. 94: 1927-1937.

32. Ong PML, Lanyon WG, Graham G, et al. (1997) Acute intermittent porphyria: the in vitro expression of mutant hydroxymethylbilane synthase. Mol. Cell. Probes 11: 293-296.

33 Llewellyn DH, Smyth SJ, Elder GH, Hutchesson AC, Rattenbury JM, Smith MF. (1992) Homozygous acute intermittent porphyria: compound heterozygosity for adjacent base transitions in the same codon of the porphobilinogen deaminase gene. Hum. Genet. 89: 97-98.

34. Branden C, Tooze J. (1991) Introduction to Protein Structure. Garland Publishing Inc., New York.

35. Alberts B, Bray D, Lewis J, Raff M, Roberts K, Watson JD. (1994) Molecular Biology of the Cell. Garland Publishing Inc., New York.

36. Thomas SD, Jordan PM. (1986) Nucleotide sequence of the hemC locus encoding porphobilinogen deaminase of Escherichia coli K12. Nucleic Acid. Res. 14: 6215-6226. 